\title{
Influence of Supporting Joints Flexibility on Statics and Stability of Steel Frames
}

\author{
Przemysław Krystosik ${ }^{1}$
}

Received: 3 April 2017 / Accepted: 20 September 2017 / Published online: 25 April 2018

(c) The Author(s) 2018

\begin{abstract}
The paper presents an influence problem of the rotational flexibility of supporting joints on steel frames behaviour. A substantial part of the paper is devoted to, neglected in the engineering practice, issue of rotational flexibility of the foundationsubgrade system. This problem was analyzed on the assumption that the foundation in the form of a rectangular rigid punch rests on a homogeneous medium of finite depth. Suitable analyses of the foundation were done using several subgrade models: Winkler's model, elastic half-space (in the classic approach) and with the use of the boundary element method, as well as HS model (hardening soil) by application of the finite elements method. The phenomenon of rotational flexibility of footings resting on a soil subgrade was analyzed within the linear range. It was shown, that the practical assessment of rotational stiffness of footings resting on subgrade can also be performed by using simple methods (e.g., based on the Winkler's model). The presented evaluation methods of the whole flexibility supported joints were used in the static and stability analyses of the certain steel frame. The presented results confirmed a significant influence of the flexibility of the supporting joints on the steel frames behaviour.
\end{abstract}

Keywords Steel frames $\cdot$ Semi-rigid joints $\cdot$ Static analysis $\cdot$ Stability analysis $\cdot$ Soil-subgrade interaction

\section{Introduction}

Due to their economic advantages, semi-rigid frames are often a subject of both empirical and theoretical research. Numerous papers have been published so far concerning semi-rigid joints (e.g., Chen et al. 2011; Kozłowski 1999; Lorenz et al. 1993), as well as frames constructed with them (e.g., Chen et al. 1996; Dhillon and O’Malley 1999; Galea 1987).

It has to be noted that the European standard code for steel structures design (EN 1993-1-8: 2005) contains relevant guidelines which allow to calculate steel frames taking into account the flexibility of internal joints (e.g. beam-tocolumn joints). However, in case of external (supporting) joints, composed of a column base and foundation embedded in the soil, the standard code (EN 1993-1-8: 2005) only allows to define the flexibility of simple column bases.

Przemysław Krystosik

krystosik@wbiis.tu.koszalin.pl

1 Faculty of Civil Engineering, Environmental and Geodetic Sciences, Koszalin University of Technology, Śniadeckich 2, 75-453 Koszalin, Poland
The herein mentioned standard, as well as other Eurocode parts lack guidelines for calculating the rotational flexibility of foundation embedded in soil. Due to this, flexibility of foundation-soil system is usually ignored in practice. Adopting the frame supporting joint in the form of a rigidly fixed foundation in soil raises some objections, because such type of support does not take into consideration the unavoidable rotation of foundation as a result of fixing moment. This phenomenon always leads to certain redistribution of displacements and internal forces in frame.

It is worth mentioning that the problem of soil-structure interaction is a well-known phenomenon. There are numerous articles on this subject (e.g., Bull 1994; Selvadurai 1979), which describe the problem in many aspects. However, the literature on this topic lacks accessible, ready-touse procedures which could be directly applied to the practical design of the steel frames with semi-rigid joints.

This paper attempts to assess the influence of foundationsoil subgrade system flexibility on statics and stability of unbraced steel frames.

Firstly, an extensive analysis was carried out of the footing foundation response resting on Winkler's subgrade and on the elastic half-space subgrade. Calculations for the 
foundation-subgrade system were also performed using numerical methods such as the boundary element method (BEM) and the finite element method (FEM). Next, all the used calculation methods were compared and their practical usefulness was evaluated.

This paper analyses influence of the rotational foundation stiffness on the statics and stability of the frame using a certain unbraced steel frame as an example. The obtained solution results significantly show that the foundation-soil interaction in frame structures is of great practical importance.

The remarks and conclusions presented herein may, according to the author's belief, be applied particularly in practical design of semi-rigid steel frames.

\section{Stiffness of Frame Supporting Joint}

Let us consider the typical, semi-rigid supporting joint of frame, subjected to the normal force $N$ and the bending moment $M$.

It can be observed that the total stiffness of that joint is composed of two stiffness kinds (Fig. 1a): stiffness $S_{1}$ of column base connected to footing foundation and the footing foundation embedded in soil. The considered supporting joint of frame can thus be mapped using the model composed of two semi-rigid joints (Fig. 1b).

The rotational stiffness of each component in the supporting joint can be described according to the relation

$S_{i}=\frac{M}{\phi_{i}}, \quad i=1,2$.

If both semi-rigid joints are located close to each other, then, based on Fig. 1b, it is easy to define the equivalent stiffness $S$ of the whole supporting joint in the elastic range ( $S_{1}=$ const. i $S_{2}=$ const. $)$.

$\phi=\phi_{1}+\phi_{2} \rightarrow \frac{1}{S}=\frac{1}{S_{1}}+\frac{1}{S_{2}}$.

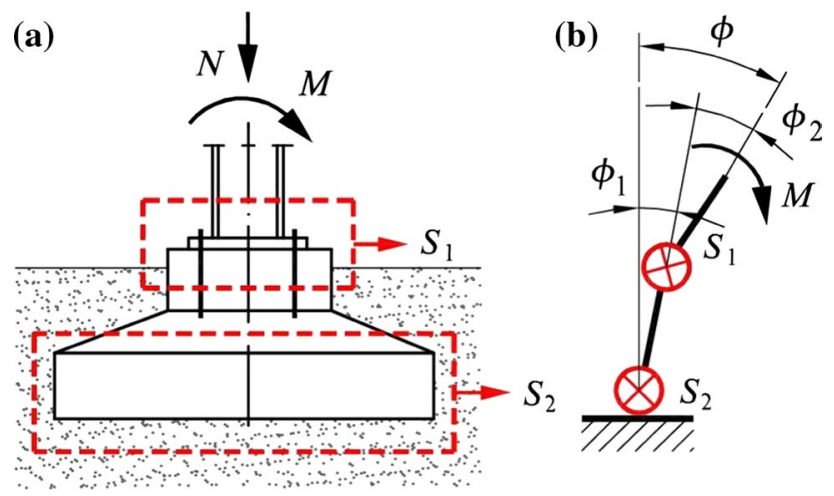

Fig. 1 Semi-rigid supporting joint: a the real joint, $\mathbf{b}$ the model of semi-rigid joint
A graphical interpretation of $\mathrm{M}-\phi$ characteristic for the individual components of the supporting joint was presented in Fig. 2. It can be easily seen that the equivalent stiffness $S$ of the analyzed supporting joint is always smaller than the stiffness of each of the support components.

The problem of determining realistic stiffness $S_{1}$ of semirigid column bases is a well-known issue, discussed e.g. in Ermopoulos and Stammatopoulos (1996, 2011). Also the Eurocode 3 (EN 1993-1-8: 2005) contains certain procedures regarding assessment of stiffness and resistance of semi-rigid column bases.

Evaluation of supporting joint stiffness $S_{2}$ causes a lot more problems in practice. There is little information in the literature about analysis and design of steel frames concerning the way of determining this kind of stiffness. Among few papers discussing this problem which the author knows about, the following papers can be mentioned (Eröz et al. 2008; Galambos 1959; Pałkowski and Krystosik 2011; Stamatopoulos 2012). It should be noted that the current European standards also lack guidelines for determining the rotational $S_{2}$ stiffness.

The correct determination of both $S_{1}$ and $S_{2}$ stiffness requires considering the normal force $N$ activity. In case of $S_{1}$ stiffness the standard (EN 1993-1-8: 2005) contains appropriate procedures taking into account both value and sign of $N$ force in calculations.

When determining the rotational stiffness $S_{2}$ of footing foundation the combined action effect of normal force $N$ and bending moment $M$ may cause relatively high stresses under foundation. It can lead to a significant reduction of the soil deformation modulus $E_{0}$, which in turn affects decrease of the total foundation-soil system stiffness. The reduction of stiffness $S_{2}$ can also be caused by partial uplift of the foundation from subgrade as a result of the normal force $N$ acting on a large eccentricity $e(M=N e)$.

To sum up, it can be stated that if in the ultimate limit state of structure, the limit stresses in soil are not exceeded, as well as the maximum value of eccentricity $e$ do is not overstepped, then stiffness $S_{2}$ can be determined using the following presented methods.

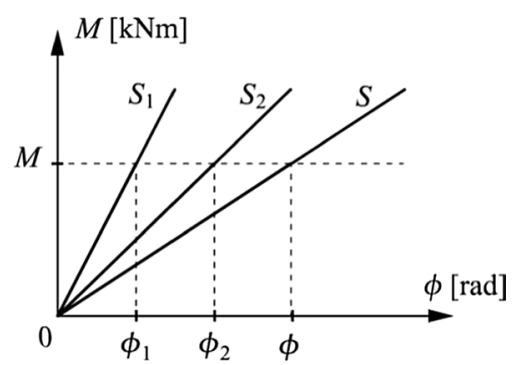

Fig. $2 M-\phi$ characteristics of supporting joint 


\subsection{Relation $\mathbf{M}-\phi$ for the Footing Foundation-Winkler's Subgrade System}

Winkler's model is the simplest single-parameter model of soil subgrade. An assumption has been made in this model that the foundation is supported on an infinite number of elastic elements that are arranged vertically on a horizontal nondeformable surface (see Fig. 3).

A constant parameter that represents stiffness of the subgrade under the foundation is the subgrade reaction coefficient $k_{s}\left[\mathrm{kN} / \mathrm{m}^{3}\right]$. Representation of response of the complex nature of the foundation-subgrade system by means of one parameter is a certain simplification, whereas accuracy of the solution obtained depends to a great extent on the properly applied value $k_{s}$.

Determining the elastic rotational stiffness $S_{2}$ of eccentrically loaded rectangular foundation can be defined by a simple formula (El Naggar and Allotey 2003):

$S_{2}=k_{s} \frac{L^{3} B}{12}$

Among many various relations used to define the subgrade reaction coefficient $k_{s}$ a very good estimation, in case of eccentrically loaded footing foundation, is obtained from the formula (Gorbunow-Posadow 1956):

$k_{s}=\frac{3 E_{0} \sqrt{\alpha}}{2\left(1-v^{2}\right) \omega \sqrt{A}}$

where $E_{0}$ is the soil deformation modulus, $A$ is an area of foundation, and the coefficient $\omega$, that depends on $\alpha=L / B$, is described with the following equation:

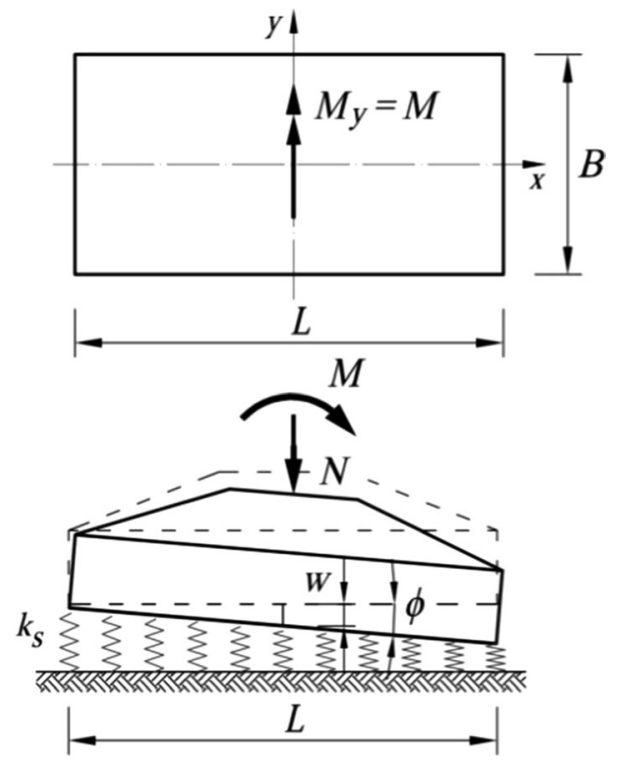

Fig. 3 Scheme of the footing foundation-Winkler's subgrade system $\omega=0.8 \alpha^{0.56}-0.2$.

The rotation angle $\phi$ value for a stiff rectangular foundation that has been eccentrically loaded and rests on Winkler's subgrade can also be determined using Taylor's formula (Bowles 1997):

$\phi=\frac{\left(1-v^{2}\right)}{E_{0}} \frac{M}{L^{2} B} m$,

where $m$ is a parameter that depends on foundation dimensions, calculated from the equation:

$m=\frac{16}{\pi\left(1+0.22 \frac{L}{B}\right)}$.

After simple transformations of the Eq. (6) may create a formula for footing foundation rotational stiffness:

$S_{2}=\frac{M}{\phi}=\frac{E_{0}}{\left(1-v^{2}\right)} \frac{L^{2} B}{m}$.

This equation was successfully used by the author for practical calculations of frames with semi-rigid supporting joints (Pałkowski and Krystosik 2011).

\subsection{Relation $M-\phi$ of the Footing Foundation-Elastic Half-space}

Formulation of a closed solution that would describe behaviour of the foundation resting on elastic half-space is possible only in few cases. For example, Borowicka (1943), using Flamant's solution presented functions that described distribution of stresses and displacements of an eccentrically loaded strip foundation for a planar problem. In his paper (Borowicka, 1943) he also presented a solution for a spatial problem of an eccentrically loaded circular punch (see Fig. 4). This relation looks as follows:

$w(x)=\frac{1-v^{2}}{2 E_{0}} \frac{N}{r}\left(1+\frac{3}{2} \frac{e x}{r^{2}}\right)$.

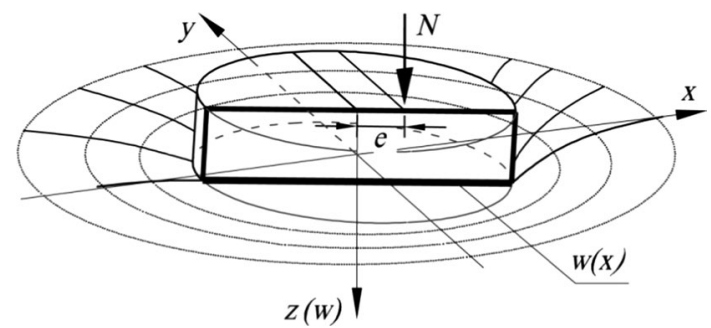

Fig. 4 Displacements of an eccentrically loaded circular punch 
On the basis of Eq. (9), and after substitution of $N e=M$, one can get a formula for rotation of a stiff circular foundation caused by the moment:

$\phi=\frac{1-v^{2}}{E_{0}} \frac{3 M}{4 r^{3}}$.

One may easily get from formula (10) a relation for rotational stiffness of a circular footing foundation:

$S_{2}=\frac{M}{\phi}=\frac{E_{0}}{1-v^{2}} \frac{4}{3} r^{3}$.

The Eq. (11) can also be used to assess rotational stiffness of a rectangular footing foundation resting on elastic subgrade. For this purpose, in formula (11) circle radius $r$ should be substituted with $\sqrt[4]{B L^{3} / 3 \pi}$ expression.

Another example of a relation that can be used to calculate the rotational stiffness of rectangular foundation is e.g. Gazetas' formula (Gazetas 1991):

$S_{2}=\frac{E_{0}}{2\left(1-v^{2}\right)} I_{y}^{0.75}\left[3\left(\frac{L}{B}\right)^{0.15}\right]$

where $I_{y}$ is the moment of inertia of the footing foundation area.

\subsection{Relation $M-\phi$ of Footing Foundation-Elastic Half-Space System from BEM}

An effective method for solving problems of foundation interaction with the elastic half-space can be achieved by applying the boundary element method (BEM), which is frequently used, along with the fine element method (FEM), in practical calculations.

Obtaining the result, which is presented as an integral equation in BEM, requires assumption of certain fundamental solution. In case of elastic half-space, such a solution will be the Bousinessq's equation (1872). Usage of the equation allows to formulate the researched problems by physical values i.e., displacements and forces (Aleynikov 1996). Thanks to this, complex engineering problems can be defined and solved in a fairly easy and efficient way.

Determination of elastic rotational stiffness for eccentrically loaded footing foundation resting on half-space, in terms of BEM, was performed using SOFISTIK software (SOFiSTiK 2011).

The foundation-soil subgrade system was modelled as a rectangular rigid punch composed of eight-node solid brick elements resting on the boundary surface of the half-space (see Fig. 5).

In the modelling process uneven division of the boundary surface was applied. The elements mesh was made denser at

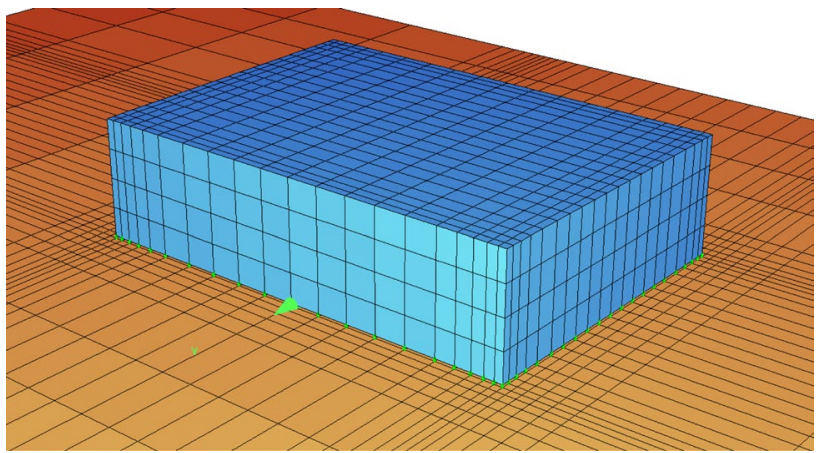

Fig. 5 Model of footing foundation resting on half-space surface

the edges and corners of the foundation i.e., in those places where stresses concentrate.

This allowed reducing the number of displacements of the analysed model that were searched for. Connection of the nodes at the setting level between the footing foundation and half-space edge was accomplished by unilateral constrains that would carry only compression.

The pressing-in loads and those rotating the foundation model were represented by surface loads applied to the top foundation surface. The calculations were performed by application of the incremental-iterative method.

\subsection{Relation $M-\phi$ of Footing Foundation-Subgrade System from FEM}

The finite element method (FEM) has been the most effective tool for solving complex engineering problems for many decades. Currently this method is a well-known and recognised tool used in design of complex civil engineering, aquatic engineering, and shipbuilding and aviation systems as well as in many other fields of science and technology.

Dimensions of soil bulk relating to the smallest foundation side $B$ have been adopted in FEM analysis of interaction between the footing foundation-soil subgrade systemsthis is illustrated in Fig. 6. This allowed to get results that would only slightly differ from those which would have been obtained for theoretically infinitely big soil volume.

The zone of contact between the foundation and subgrade was modelled by applying discrete elements carrying only compression.

To minimise the number of unknown displacements, half of the foundation-subgrade system with properly considered boundary conditions (see Fig. 7) was directly analysed. Furthermore, uneven division of the model into finite elements was used to discretize more intensely those elements, in which concentration of stress occurs.

The loading method and calculations were applied in the same ways as in BEM analysis. 


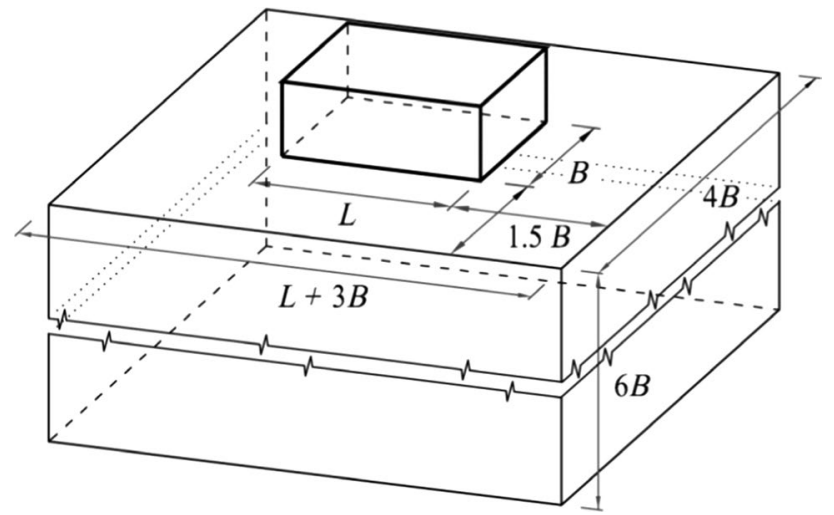

Fig. 6 External dimensions of the analysed soil bulk

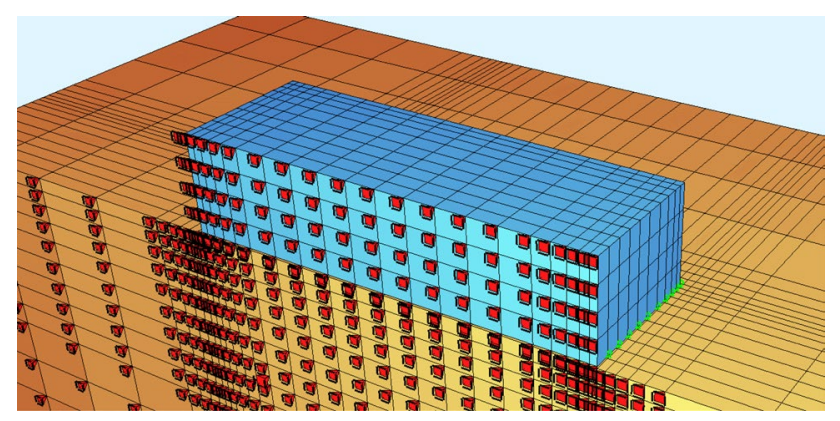

Fig. 7 Footing foundation model

HS (hardening soil) model was used in the FEM calculations (Benz 2006). This model takes into account such phenomena as variability of soil stiffness, plastic flow effects, and soil volume changes during compression-compaction or dilatancy, or compaction during compression. The plasticization process and isotropic hardening associated with it are controlled by a maximum of four plastic surfaces. Additionally, in HS model it is important to give consideration to the non-linear relations between the stress condition in the subgrade and its stiffness. Using relevant power expressions, values of the following moduli were made conditional on effective stress; this pertains to the primary loading modulus $-E_{\text {oed }}, E_{50}$, and unload-reload modulus $-E_{\text {oed }}$. This allows illustrating the response of the building - subgrade system taking into account non-linear relationship $\sigma-\varepsilon$ of soil in the area of large, and partly small, strains.
Table 2 Soil subgrade parameters

\begin{tabular}{ll}
\hline Soil parameters defined in tests (Larsson 2001) & \\
Soil weight $\gamma$ & $20.9 \mathrm{kN} / \mathrm{m}^{3}$ \\
Internal friction angle $\varphi$ & $32^{\circ}$ \\
Cohesion $c$ & $12 \mathrm{kPa}$ \\
Poisson's ration $v$ & 0.25 \\
Lateral pressure coefficient $k_{o}$ & 0.5 \\
Parameters defined during the calibration process & \\
Modulus $E_{0}$ & $65 \mathrm{MPa}$ \\
Modulus $E_{50}$ & $24 \mathrm{MPa}$ \\
Modulus $E_{\text {oed }}$ & $24 \mathrm{MPa}$ \\
Modulus $E_{u r}$ & $120 \mathrm{MPa}$ \\
Power index $m$ & 0.3 \\
Failure factor $R_{f}$ & 0.95 \\
Reference pressure $p_{\text {ref }}$ & $100 \mathrm{kPa}$ \\
\hline
\end{tabular}

\section{Analysis of Rotational Stiffness in a Rectangular Footing Foundation}

Based on the presented subgrade models and described computation methods, a parametric analysis of rotational stiffness for selected footing foundations resting on soil subgrade was performed. Stiffness was determined for various proportions of footing foundation sides $\alpha=L / B$ within the range from $1 / 3$ to 3 , with preservation of the same surface area $A$ of $2 \mathrm{~m}^{2}$ (see Table 1).

Averaged, experimentally defined, geotechnical parameters of subgrade profile (Larsson 2001) and values determined in BEM and FEM models (see Table 2) were used in calculation.

During the calibration process of soil parameters the results of experimental test PLT (plate loading test) were used (Larsson 2001). They were performed on stiff square foundation featuring side length of $1 \mathrm{~m}$. Comparison of the PLT test with numerical calculations of settlement for the foundation is illustrated in Fig. 8.

As one can easily note, the real soil subgrade responds as elastic continuum in case of small stress values. For this reason displacements calculations of foundation can be herein obtained with the use of linear subgrade models (e.g., Winkler's soil model, elastic half-space).

However, causing in the soil relatively large stresses leads to the appearance of nonlinear strain increase. In such cases the analysis of foundation-subgrade system
Table 1 Listing of foundation dimensions in projection

\begin{tabular}{llllllll}
\hline$\alpha=\frac{L}{B}$ & $\frac{1}{3}$ & $\frac{1}{2}$ & $\frac{2}{3}$ & 1 & $\frac{3}{2}$ & 2 & 3 \\
\hline$L(\mathrm{~m})$ & 0.816 & 1 & 1.155 & 1.414 & 1.732 & 2 & 2.449 \\
$B(\mathrm{~m})$ & 2.449 & 2 & 1.732 & 1.414 & 1.155 & 1 & 0.816 \\
\hline
\end{tabular}




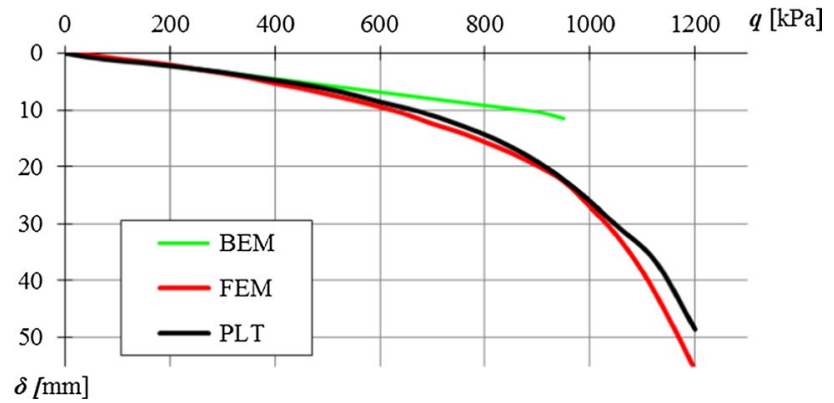

Fig. 8 Comparison of $q-\delta$ relations obtained for various subgrade models

is much more difficult, yet possible by applying methods and models which take into account the physical nonlinearity of soil. For this purpose the incremental-iterative FEM analysis can be applied with the use of advanced soil model, e.g. HS model.

The objective parametric analysis was carried out, vertical load applied at the foundation level was assumed as $N=400 \mathrm{kN}$, which is equivalent to the averaged value of the bearing pressure $q_{0}=200 \mathrm{kPa}$. To compare, the maximum value of the bearing pressure calculated according to (EN 1997-1: 2007) for the analysed foundations is approx. 800-900 kPa. It can therefore be assumed that the obtained results for adopted loads and in the range of small foundations rotations are reliable for all used models and methods.

The deformation modulus $E_{0}$, being a measure of soil stiffness, was used in calculations of stiffness $S_{2}$ for foundations resting on the Winkler's subgrade, half-spaces in classical form and BEM. The remaining deformation moduli were used in FEM calculations.

While performing calculations by application of FEM, the initial stress state in the subgrade was taken into account in accordance with the formula $\sigma(z)=\gamma z$, whereas in the other cases a weightless subgrade models were applied.
Determined values for the rotational stiffness $S_{2}$ of footing foundations for the analysed ratios $\alpha=L / B$ are presented in Table 3.

Examples of relations $M-\phi$ foundation-subgrade systems were graphically illustrated in Figs. 9, 10 and 11.

Comparison of footing foundations stiffness $S_{2}$ for sides proportions of $\alpha=0.5$ and $\alpha=2$ was presented in Fig. 12.

Based on the presented analysis results one can easily see a fairly obvious dependence of the foundation-subgrade system stiffness on the footing foundation dimensions, i.e., the higher the $L / B$ ratio, the larger the rotational stiffness of the foundation.

Application of numerical methods (BEM and FEM) in solving the foundation-subgrade interaction problem allowed to verify the results obtained from simple formulae (3), (8), (11) and (12). By analyzing the obtained results in detail it can be seen that on average, the smallest values of rotational stiffness $S_{2}$ were obtained using formula (3) whereas the largest ones-using the FEM method. The differences between the stiffness extreme values amount to approx. $40 \%$. It is worth noting that the average differences between the results originating from application of FEM and from formula (8) are smaller and amount to slightly more than $20 \%$.

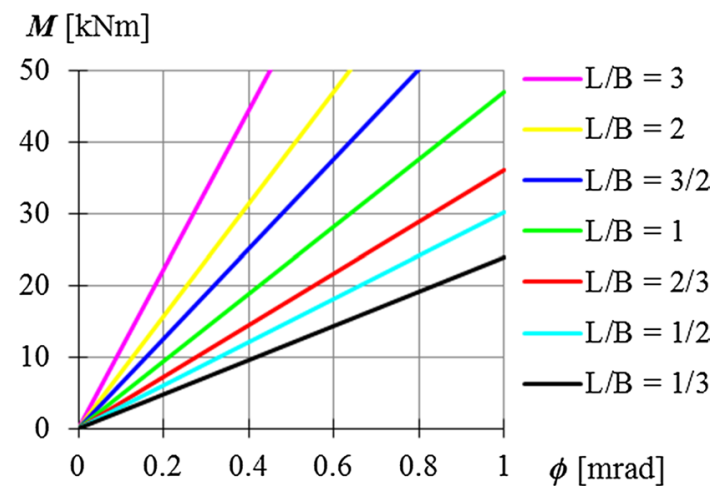

Fig. 9 Characteristics of stiffness $S_{2}$ determined for Winkler's subgrade from formula (8)
Table 3 Values of $S_{2}$ stiffness $[\mathrm{kN} \mathrm{m} / \mathrm{rad}]$

\begin{tabular}{|c|c|c|c|c|c|c|c|}
\hline$\alpha=\frac{L}{B}$ & $\frac{1}{3}$ & $\frac{1}{2}$ & $\frac{2}{3}$ & 1 & $\frac{3}{2}$ & 2 & 3 \\
\hline \multicolumn{8}{|c|}{ Winkler's subgrade } \\
\hline$S_{2}$ acc. to (3) & $2.03 \times 10^{4}$ & $2.53 \times 10^{4}$ & $3.05 \times 10^{4}$ & $4.09 \times 10^{4}$ & $5.60 \times 10^{4}$ & $7.08 \times 10^{4}$ & $9.95 \times 10^{5}$ \\
\hline$S_{2}$ acc. to (8) & $2.39 \times 10^{4}$ & $3.02 \times 10^{4}$ & $3.61 \times 10^{4}$ & $4.70 \times 10^{4}$ & $6.27 \times 10^{4}$ & $7.84 \times 10^{4}$ & $1.11 \times 10^{5}$ \\
\hline \multicolumn{8}{|l|}{ Elastic half-space } \\
\hline$S_{2}$ acc. to $(11)$ & $2.13 \times 10^{4}$ & $2.89 \times 10^{4}$ & $3.59 \times 10^{4}$ & $4.86 \times 10^{4}$ & $6.59 \times 10^{4}$ & $8.18 \times 10^{4}$ & $1.11 \times 10^{5}$ \\
\hline$S_{2}$ acc. to (12) & $1.70 \times 10^{4}$ & $2.45 \times 10^{4}$ & $3.17 \times 10^{4}$ & $4.56 \times 10^{4}$ & $6.57 \times 10^{4}$ & $8.51 \times 10^{4}$ & $1.23 \times 10^{5}$ \\
\hline \multicolumn{8}{|l|}{ BEM } \\
\hline$S_{2}$ & $2.21 \times 10^{4}$ & $3.03 \times 10^{4}$ & $3.74 \times 10^{4}$ & $5.03 \times 10^{4}$ & $6.91 \times 10^{4}$ & $8.76 \times 10^{4}$ & $1.54 \times 10^{5}$ \\
\hline \multicolumn{8}{|l|}{ FEM } \\
\hline$S_{2}$ & $2.64 \times 10^{4}$ & $3.75 \times 10^{4}$ & $4.42 \times 10^{4}$ & $5.68 \times 10^{4}$ & $7.63 \times 10^{4}$ & $9.70 \times 10^{4}$ & $1.36 \times 10^{5}$ \\
\hline
\end{tabular}




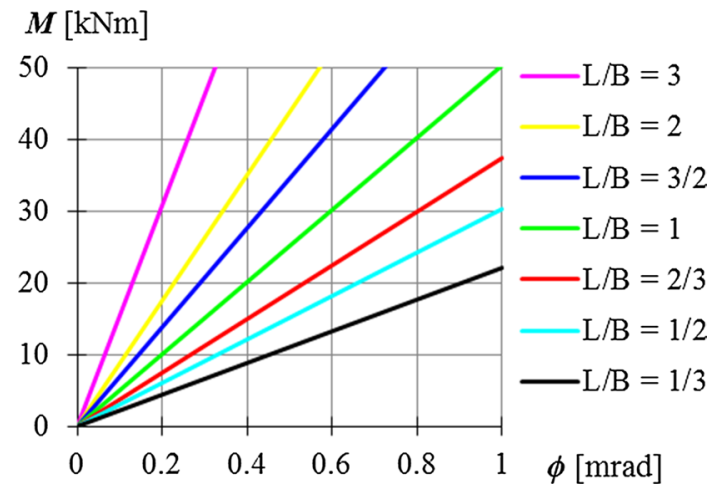

Fig. 10 Characteristics of stiffness $S_{2}$ determined by application of BEM method

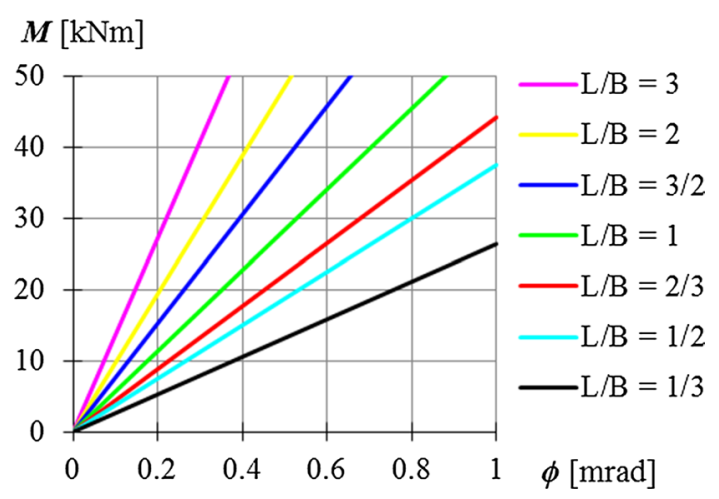

Fig. 11 Characteristics of stiffness $S_{2}$ determined by application of FEM method

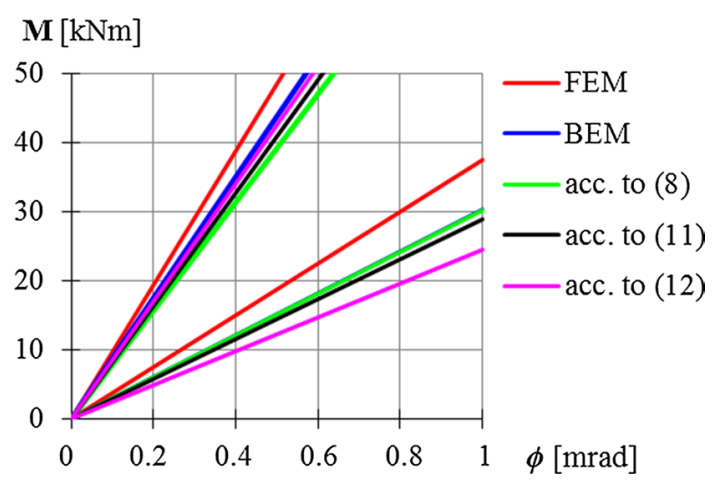

Fig. 12 Graphical comparison of stiffness $S_{2}$ for sides proportions of $\alpha=1 / 2$ and $\alpha=2$

In summary, it can therefore be stated that the computer methods used in the analysis confirm a high usefulness of equations presented in the work, in particular formula (8). These equations, according to the author, can be successfully used in practical evaluation of footings foundation stiffness.

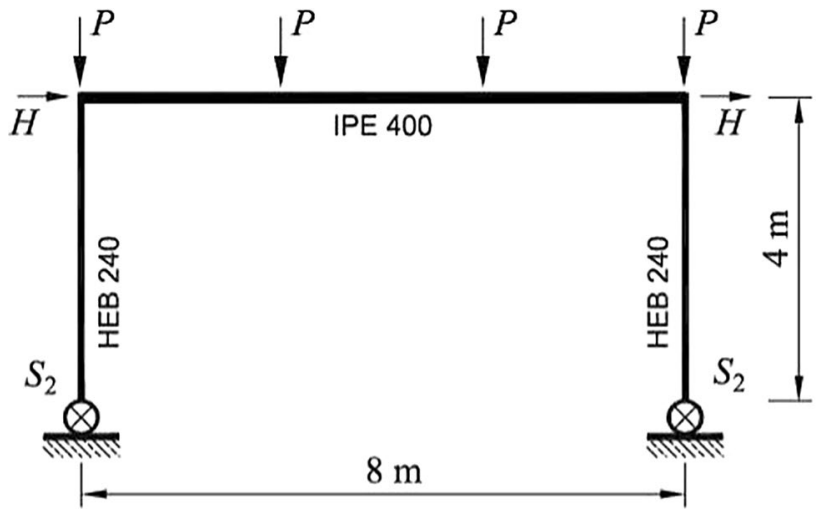

Fig. 13 Analysed frame static diagram

\section{A Numerical Example of Steel Frame Analysis}

Influence of rotational flexibility of the supporting joints on behaviour of steel frame was presented on a certain example. The static calculations were performed using the second-order elastic analysis, while the stability calculations were made with the use of the eigenvalues method of matrix stiffness. Both kinds of analysis were performed using the Sofistik software.

The subject matter of calculations is a single-storey frame with flexible supporting joints (see Fig. 13). Those joints take into account both the stiffness $S_{1}$ of column base and the stiffness $S_{2}$ of footing foundation-soil subgrade system.

Data: $P=120 \mathrm{kN}, H=20 \mathrm{kN}, \mathrm{S} 355$ steel, elasticity modulus of steel: $E=210 \mathrm{GPa}$, frame beam: IPE 400 , frame columns: HEB 240, foundation concrete: C 25/30, soil subgrade parameters: sandy clay, cohesion of soil: $c=15 \mathrm{kPa}$, internal friction angle: $\varphi=32^{\circ}, E_{0}=40 \mathrm{MPa}, v=0.25$.

In the adopted frame system, static analysis was commenced with an assumption that all frame joints are stiff (case I). Calculation results for this case, in form of bending moments distribution and values of the top frame beam displacements, are presented in Fig. 14a.

The force system acting on more loaded support is shown in Fig. 14b; values of the forces are: $M_{E d}=136.2 \mathrm{kN} \mathrm{m}$, $N_{E d}=308.6 \mathrm{kN}, V_{E d}=91.1 \mathrm{kN}$. For those forces respectively, column base (see Fig. 15a) and footing foundation (see Fig. 15b) were designed in accordance with standards (EN 1993-1-8: 2005) and (EN 1997-1: 2007).

The foundation was designed in such a way so that obtained force system acting on the footing foundation (assuming linear distribution of bearing pressure) would not cause uplift of foundation surface from the subgrade. With this assumption made, value of stresses under the footing foundation centre is equal to $19 \%$, and under more heavily 


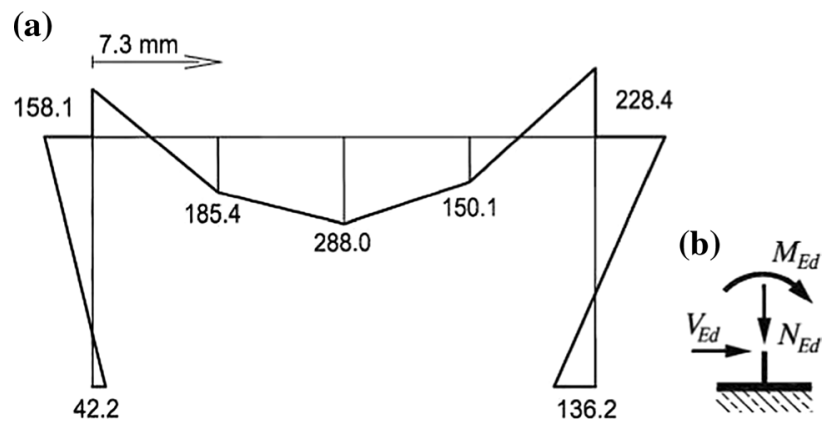

Fig. 14 Results of static calculations: a distribution of bending moment $[\mathrm{kN} \mathrm{m}]$ in frame (case I), $\mathbf{b}$ force system acting on the right support

loaded footing foundation edge- $38 \%$ of the ultimate bearing pressure $q_{u}=899 \mathrm{kPa}$.

During the course of supporting joint design, rotational stiffness of both components were determined: $S_{1}=38.86 \times 10^{3} \mathrm{kN} \mathrm{m} / \mathrm{rad}$ and $S_{2}=40.61 \times 10^{3} \mathrm{kN} \mathrm{m} / \mathrm{rad}$. It is easy to see that in the analysed example stiffness of foundation-soil system $\left(S_{2}\right)$ is very close to stiffness of column base $\left(S_{1}\right)$.

Designated stiffness of supporting joint components were used in the static analysis, where the influence of stiffness $S_{1}$ and stiffness $S_{2}$ of supporting joints (case II) were separately considered. Results of this analysis were presented in Fig. 16 (values in brackets refer to calculation of frame with stiffness $S_{1}$ taken into account).

Analogous calculations of the frame were made with the use of equivalent stiffness $S$ of the whole supporting joint (the total influence of stiffness $S_{1}$ and $S_{2}$ was taken into account; case III). Stiffness of the whole supporting joint, calculated according to (2) amounts to $S=19.86 \times 10^{3} \mathrm{kN} \mathrm{m} /$ $\mathrm{rad}$. Results of the static analysis with taking into account the equivalent stiffness $S$ of the supports are presented in Fig. 17.

Taking into account the rotational flexibility of supporting joint in structural analysis caused obtaining more realistic values of internal forces and displacements in the frame. First and foremost, values of moments decreased considerably in cross-sections of columns adjacent to supports. In the right, more loaded column, values of the bending moments decreased by approx. $39 \%$. Horizontal displacements of the frame beam increased by $60 \%$.

Based on the newly obtained forces acting on the right column supporting joint: $M_{E d}=83.7 \mathrm{kN} \mathrm{m}, N_{E d}=311.1 \mathrm{kN}$, $V_{E d}=78.5 \mathrm{kN}$, and based on the guidelines of standard (EN 1997-1: 2007), new dimensions of the footing foundation in its projection were defined as: $L=1.5 \mathrm{~m}, B=1 \mathrm{~m}, e_{0}=0.3 \mathrm{~m}$ (see Fig. 15b). For smaller dimensions of the footing foundation the maximum value of the ultimate bearing pressure was
Fig. 15 Supporting joint: a column base, $\mathbf{b}$ footing foundation (a)

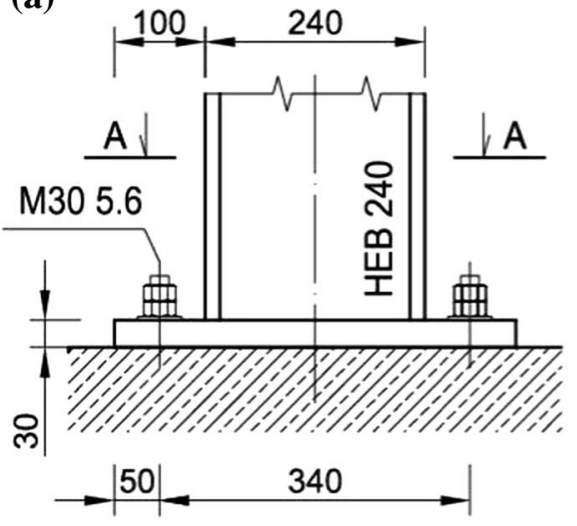

(b)
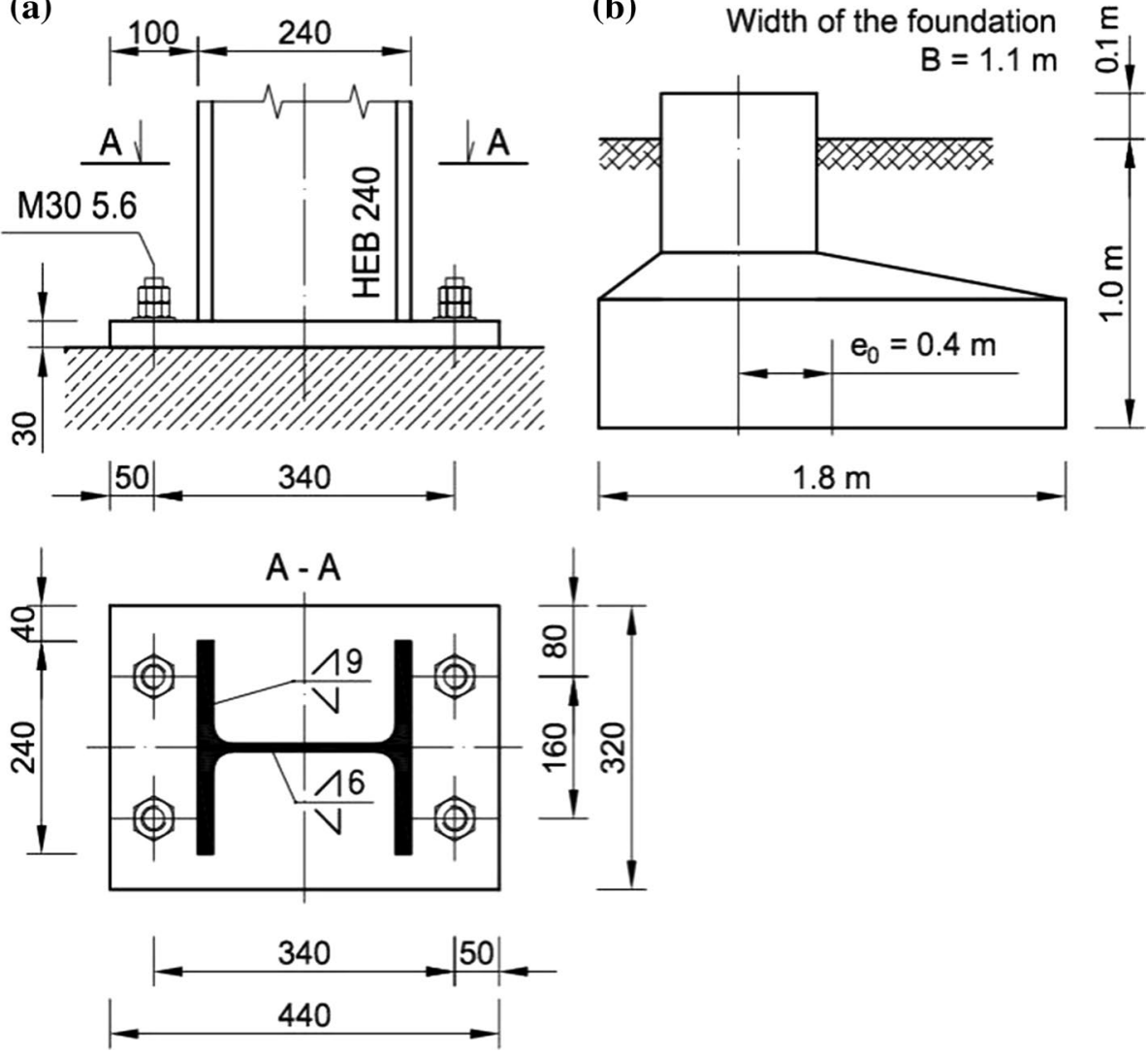


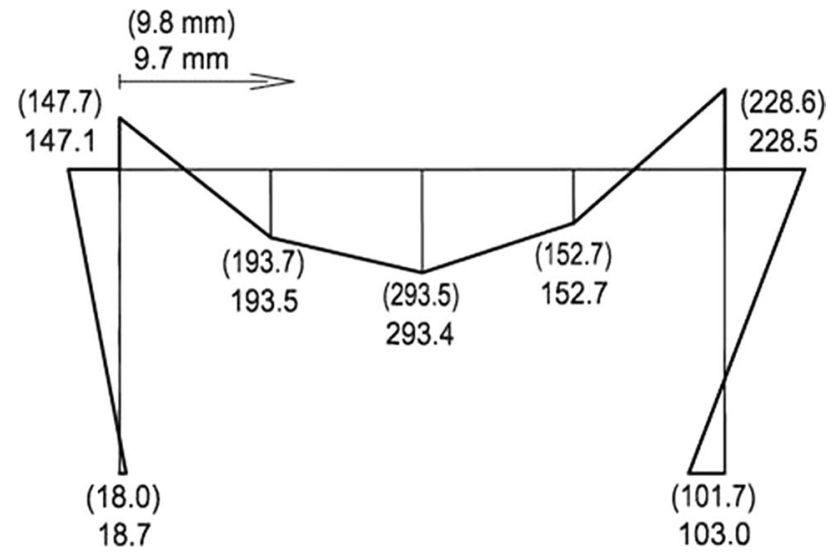

Fig. 16 Distribution of bending moments $[\mathrm{kN} \mathrm{m}]$ in frame (case II)

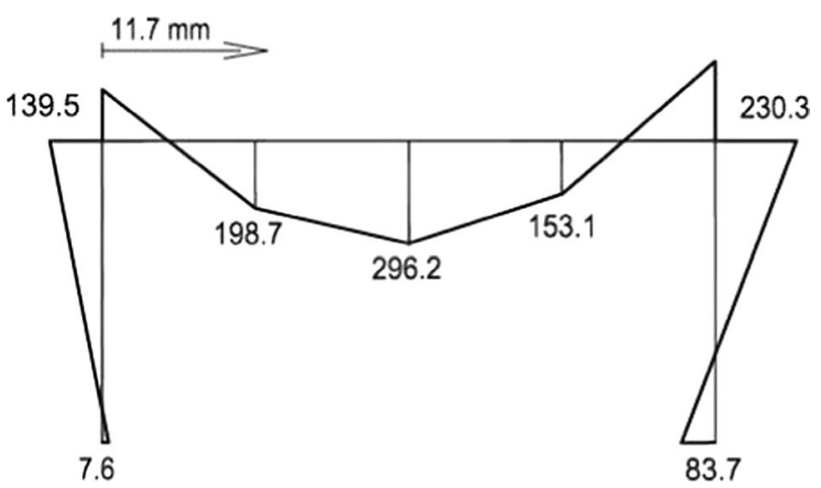

Fig. 17 Distribution of bending moments [ $\mathrm{kN} \mathrm{m}]$ in frame (case III)

$q_{u}=936 \mathrm{kPa}$. The calculated values of stress under the centre of gravity and at the edge of foundation compressed zone were approx. 23 and $44 \%$ of $q_{u}$ respectively. The change of forces system acting on the supporting joint and adoption of the smaller dimensions of footing foundation caused reduction of stiffness to the values: $S_{1}=35.67 \times 10^{3} \mathrm{kN} \mathrm{m} /$ rad, $S_{2}=25.10 \times 10^{3} \mathrm{kN} \mathrm{m} / \mathrm{rad}$ and $S=14.73 \times 10^{3} \mathrm{kN} \mathrm{m} / \mathrm{rad}$.

Static calculations for the frame of updated supporting joints stiffness $\left(S=14.73 \times 10^{3} \mathrm{kN} \mathrm{m} / \mathrm{rad}\right)$ caused a further redistribution of internal forces and displacements (case IV). Results of the analysis are shown in Fig. 18.

Subsequent reduction of the footing foundation dimensions had no significant influence on further change of internal force values in frame. For this reason, the calculations were stopped at this stage.

Apart from static calculations the stability analysis of the considered frame was also performed, but loaded only by two vertical forces acting on top corner nodes of the frame (see Fig. 13).

To determine the values of critical forces $N_{c r}$ in frame columns the eigenvalues method of matrix stiffness was used. Values of the effective length coefficient $\mu$ of columns $\left(L_{c r}=\mu h\right)$ were calculated using formulas:

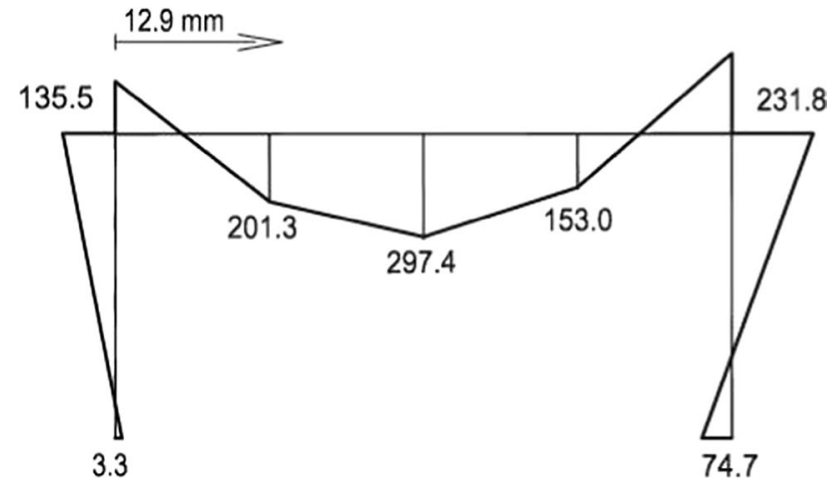

Fig. 18 Distribution of bending moments $[\mathrm{kN} \mathrm{m}]$ in frame (case IV)

Table 4 Results of the stability analysis

\begin{tabular}{lll}
\hline Stiffness [kN m/rad] & $\begin{array}{l}\text { Critical force } \\
N_{c r}[\mathrm{kN}]\end{array}$ & $\begin{array}{l}\text { Coefficient } \mu \\
\text { acc. to (12) }\end{array}$ \\
\hline $\begin{array}{ll}\text { Frame with rigid joint; case I } \\
\quad\end{array}$ & 10,279 & 1.19 \\
$\quad \begin{array}{l}\text { Frame with semi-rigid joint; case II } \\
\quad\end{array}$ & 8143 & 1.34 \\
$S_{1}=38.86 \times 10^{3}$ & 8214 & 1.33 \\
$S_{2}=40.61 \times 10^{3}$ & & \\
Frame with semi-rigid joint; case III & 6899 & 1.45 \\
$\quad S=19.86 \times 10^{3}$ & & \\
Frame with semi-rigid joint; case IV & & 1.52 \\
$\quad S=14.76 \times 10^{3}$ & 6295 & \\
\hline
\end{tabular}

$N_{c r}=\frac{\pi^{2} E I}{(\mu h)^{2}} \rightarrow \mu=\frac{\pi}{h} \sqrt{\frac{E I}{N_{c r}}}$,

where $E I$ is column stiffness and $h$ is height of frame column.

Results of the analysed frame with rigid joint (case I) and frame with semi-rigid supporting joints (case II, III, IV) were presented in Table 4.

The calculated value of the critical force $N_{c r}$ in frame columns with semi-rigid joint (case IV) is $39 \%$ lower than the value of that force in frame with rigid joints. This fact causes $28 \%$ increase of the frame's effective column length with semi-rigid joints.

\section{Summary and Final Remarks}

The paper discusses the issue of rotational flexibility of the footing foundation-soil system and influence of that flexibility on steel frame behaviour.

The first part of the study presents assessment methods of the linear foundation-subgrade system stiffness, using various subgrade models for this purpose. Based on the 
parametric analysis results, it has been demonstrated that in practical design process fairly simple formulae, such as, for example, formula (8) can be used for rotational stiffness determination of rectangular foundations.

However, it should be remembered that accuracy of foundation stiffness assessment depends, to a high extent, on the accuracy of defining subgrade parameters i.e. $E_{0}$ and $v$.

In the second part of this paper, the influence of foundation flexibility on internal forces values and displacements in steel frames was demonstrated using a certain example. On the basis of the analysis results, one can easily note that taking into account the rotational flexibility of frame supporting joint considerably improves real response representation of the entire structure. This allows designing more economically not only the steel frames but also the foundations.

The models and methods for determining elastic rotational stiffness values for the foundation-subgrade system presented herein can be applied if the foundation loading would not cause:

- expansion of the soil yield in the compressed zone under the foundation,

- uplift of the foundation from the soil subgrade in the tensioned zone.

To comply with the first condition, one should limit values of stress in the foundation level down to a certain intransgressible value. In the literature on the subject, e.g. (Bowles 1997), the maximum average stress under the foundation equals from 30 to $50 \%$ of the ultimate bearing pressure $q_{u}$ calculated using (EN 1997-1: 2007) formula.

Compliance with the second condition requires such foundation design where maximum values of the eccentrically acting force $N$ are not exceeded because then stress in the soil subgrade under less loaded foundation edge disappears.

To sum up, the phenomenon of supporting joints flexibility has a very important influence on statics and stability of steel frames. It should be noted that in many practical cases, the columns bases and the foundations can have similar values of rotational stiffness. It means that both kinds of supports components, in similar degree, have influence on steel frames behaviour. In such cases in particular, taking into account the flexibility of both components in frames analysis always leads to obtaining more accurate solutions.

Open Access This article is distributed under the terms of the Creative Commons Attribution 4.0 International License (http://creativeco mmons.org/licenses/by/4.0/), which permits unrestricted use, distribution, and reproduction in any medium, provided you give appropriate credit to the original author(s) and the source, provide a link to the Creative Commons license, and indicate if changes were made.

\section{References}

Aleynikov, S. M. (1996). A boundary-integral equation approach for foundations resting on a deformable half-space with limit contact pressure. International Journal for Numerical and Analytical Methods in Geomechanics, 20, 617-634.

Benz, T. (2006). Small-strain stiffness of soils and its numerical consequences (Ph.D. thesis). Institut fur Geotechnik der Universitat Stuttgart, Stuttgart.

Borowicka, H. (1943). Über ausmittig belastete, starre Platten auf elastisch-isotropen Untergrund. Ingenieur-Archiv, 14(1), 1-8.

Bowles, J. E. (1997). Foundation analysis and design (5th ed.). New York: McGraw-Hill Co.

Bull, J. W. (1994). Soil-structure interaction: Numerical analysis and modelling. London: E. \& F. N Spon.

Chen, W. F., Goto, Y., \& Liew, J. Y. R. (1996). Stability design of semirigid frames. New York: Wiley.

Chen, W. F., Kishi, N., \& Komuro, M. (2011). Semi-rigid connection. Handbook. Fort Lauderdale: J. Ross Publication.

Dhillon, B. S., \& O'Malley, J. W. (1999). Interactive design of semi-rigid steel frames. Journal of Structural Engineering, 125(5), 556-564.

El Naggar, M. H., \& Allotey, N. (2003). Analytical moment-rotation curves for rigid foundations based on a Winkler model. Soil Dynamics and Earthquake Engineering, 23, 367-381.

Ermopoulos, J. Ch., \& Stammatopoulos, G. N. (1996). Mathematical modelling of base plate connections. Journal of Steel Research, 36(2), 79-100.

Ermopoulos, J. Ch., \& Stammatopoulos, G. N. (2011). Experimental and analytical investigation of steel column bases. Journal of Constructional Steel Research, 67, 1341-1357.

Eröz, M., White, D. W., \& Des Roches, R. (2008). Direct analysis and design of steel frames accounting for partially restrained column base conditions. Journal of Structural Engineering, 9(134), 1508-1517.

Eurocode 3. EN 1993-1-8 (2005). Design of steel structures - Part 1-8: design of joints.

Eurocode 7. EN 1997-1 (2007). Geotechnical design - Part 1: general rules.

Galambos, T. V. (1959). Influence of partial base fixity on the buckling strength of rigid frames (progress report-36) (p. 1754). Paper: Fritz Laboratory Reports.

Galea, Y. (1987). Non-linear analysis of plate frame structures with semi-rigid connection. In Proceedings of 5 connection in steel structures conference (pp. 222-229). France.

Gazetas, G. (1991). Foundation vibrations. Foundation engineering handbook (2nd ed.). New York: Van Nostrand Reinhold.

Gorbunow-Posadow, M. I. (1956). Structures calculation on elastic subgrade (in Polish). Warsaw: Budownictwo i Architektura.

Kozłowski, A. (1999). A review of models of semi-rigid steel columnbeam connections. Archives of Civil Engineering, 42, 65-82.

Larsson, R. (2001). Investigations and load tests in clay till. Linköping: Swedish Geotechnical Institute.

Lorenz, R. F., Kato, B., \& Chen, W. F. (1993). Semi-rigid connection in steel frames. New York: McGrow-Hill.

Pałkowski, Sz., \& Krystosik, P. (2011). Static analysis of steel frames with semi-rigid supporting joints. In Proceedings of 12th international conference on metal structures (pp. 589-608). Poland.

Selvadurai, A. P. (1979). Elastic analysis of soil-foundation interaction. Amsterdam: Elsevier Scientific Publishing Company.

SOFiSTiK. (2011). Halfspace analysis for static soil-structure interaction. Oberschleissheim: SOFiSTiK AG.

Stamatopoulos, G. N. (2012). Contribution of the flexible supports to the distribution of the internal forces in steel frames. International Journal of Steel Structures, 12(3), 419-426. 